\section{Pensar la historia}

${ }^{1}$ Erwin Silva

\section{Recibido: 13 de agosto de 2012 / Aprobado: 15 de agosto de 2012}

\section{Introducción}

Toda reflexión sobre la historia es un pensamiento especulativo vinculado a un sistema metafísico o a una visión trascendente de los acontecimientos humanos, tanto como a un mito y una utopía al principio y al final del trayecto histórico. Ejemplo de esto es G.W.Hegel que incluso llega a pensar en un fin de la historia cuando hace, su recorrido el Espíritu que es la Idea de la libertad en camino al absoluto. ${ }^{2}$

\section{La historia como libro}

La invención del género "historia" por los griegos antiguos es un acto de la memoria (Mnemosyne) cuyo paso a la escritura significó el registro de los hechos humanos significativos y el sentido de arraigo de un pueblo a una tierra madre. De esto se infiere que hay una visión del Otro, en este caso desde Grecia se ve a los persas.

Es en Grecia del siglo V. a. C cuando la Historia nace al Libro más allá del recital de los mitos de los dioses, los semidioses y los héroes y de los relatos de periplos. La polis griega es el ámbito político que posibilita la aparición de la Historia así como de la Filosofía. Sólo que la Filosofía se constituirá luego en una consideración reflexiva de la Historia, lo que llamamos hoy Filosofía de la Historia.

El espíritu griego con que se elabora la Historia es el de una ligazón estrecha a la acción, a los seres que protagonizan los sucesos o los acontecimientos en un espacio agonal. Además de la dualidad con los barbaros inventada por los griegos, la dicotomía civilización - barbarie persistirá hasta nuestros días creando discriminación, conquistas y guerras.

El hecho histórico fundamental en los primeros libros de Historia es la guerra, un fasto que se describe junto a una encuesta de tierras, pueblos y costumbres. Aquí me refiero a Heródoto y sus Nueve libros de Historia donde congrega ananké y destino. ${ }^{3}$ Para Herodoto historia es averiguación.

1 Docente Investigador del Área de Educación para la Paz y los Derechos Humanos. Instituto de Investigaciones "Martin Luther King" (UPOLI).

2 GWF Hegel: Lecciones sobre Filosofía de la Historia Universal. Alianza Editorial, Madrid, 2001.

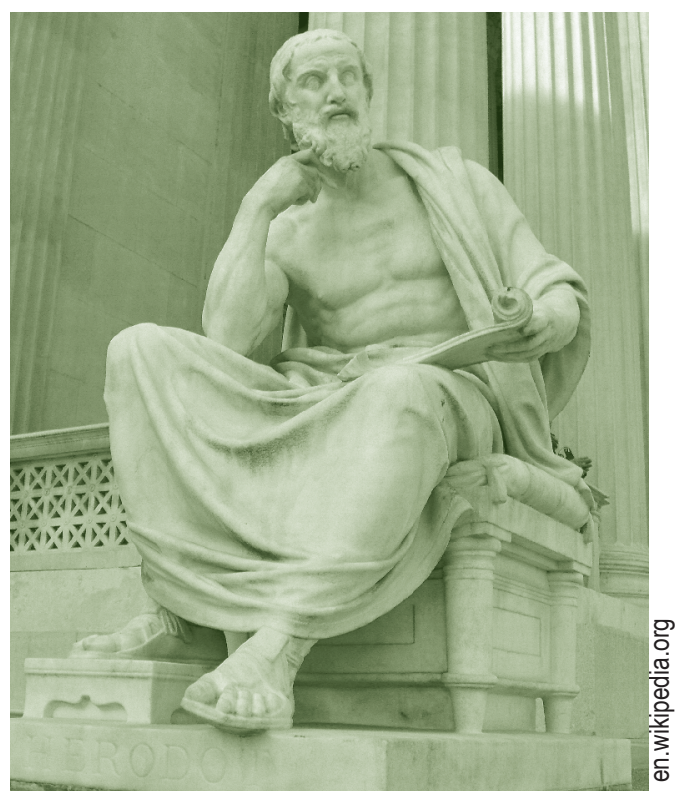

\section{RESUMEN}

Este es el primero de tres artículos consecutivos sobre la filosofía de la Historia. El propósito de este primer artículo es presentar desde la filosofía de la historia un posible origen de la historia en la cultura occidental y un somero recorrido por algunos de los exponentes de esta Ciencia y de cómo se convierte la historia en historia escrita.

Palabras clave: Filosofía de la historia, historia, cultura, ciencia histórica.

\section{ABSTRACT}

This is the first of three consecutive articles on the philosophy of history. The purpose of this first article is to present from the philosophy of history, a possible origin from history in Western culture and a brief travel of some of the exponents of this science and how the history turns in recorded history.

Keywords: Philosophy of History, history, culture, science historically. 
El historiador en un vértice es un narrador, interpreta los hechos, escribe su propia novela, toda vez que es imposible revivir el hecho histórico aun viviéndolo coetáneamente, el hecho está en el punto de mira del observador que puede ser beligerante como Tucídides. ${ }^{4}$ Tucídides es el testigo de la guerra entre Atenas y los peloponesios.

Se escribe esta historia de guerra y paz, de los artificios y las formas políticas, y sobre todo, se describe la acción puramente humana sin intervención divina o al menos pretendiendo desligarse de los designios de las divinidades.

Es posible ver en Tucídides que la historia se recupera también como discurso y análisis y como lección para la posteridad. (Discurso fúnebre a Pericles).

Polibio juntará sus Historias (Historiae) a esta constelación de historiadores que darán nombre y principios a esta ciencia que denominamos historia y que aun sigue echando sus propios fundamentos para ser una disciplina científica.

Jenofonte, por quien sabemos de Sócrates, con su "Anábasis o Expedición de los diez mil", confirma que la Historia en principio puede ser narración, averiguación, novela, estrategia o relatos de una expedición militar. ${ }^{5}$

Los romanos, voluntariosa prolongación de los griegos, continúan la labor del libro

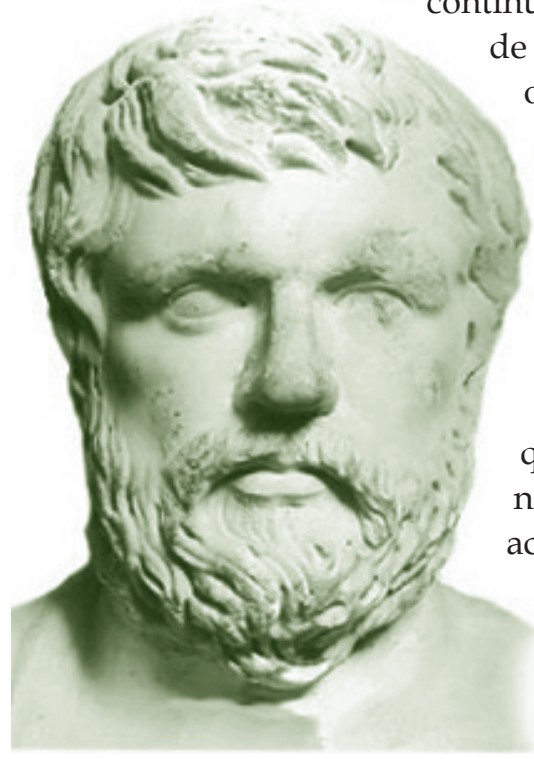

bauldetrompetillas.creacicle.com de historia, y proliferan otros géneros tales como la crónica de guerra (Julio César), las biografías (Suetonio), las vidas paralelas (Plutarco), los anales (Tácito) la ucronía y el epítome que da orden a la narración de los acontecimientos (Tito Livio).

\section{Conclusiones}

Este breve recorrido

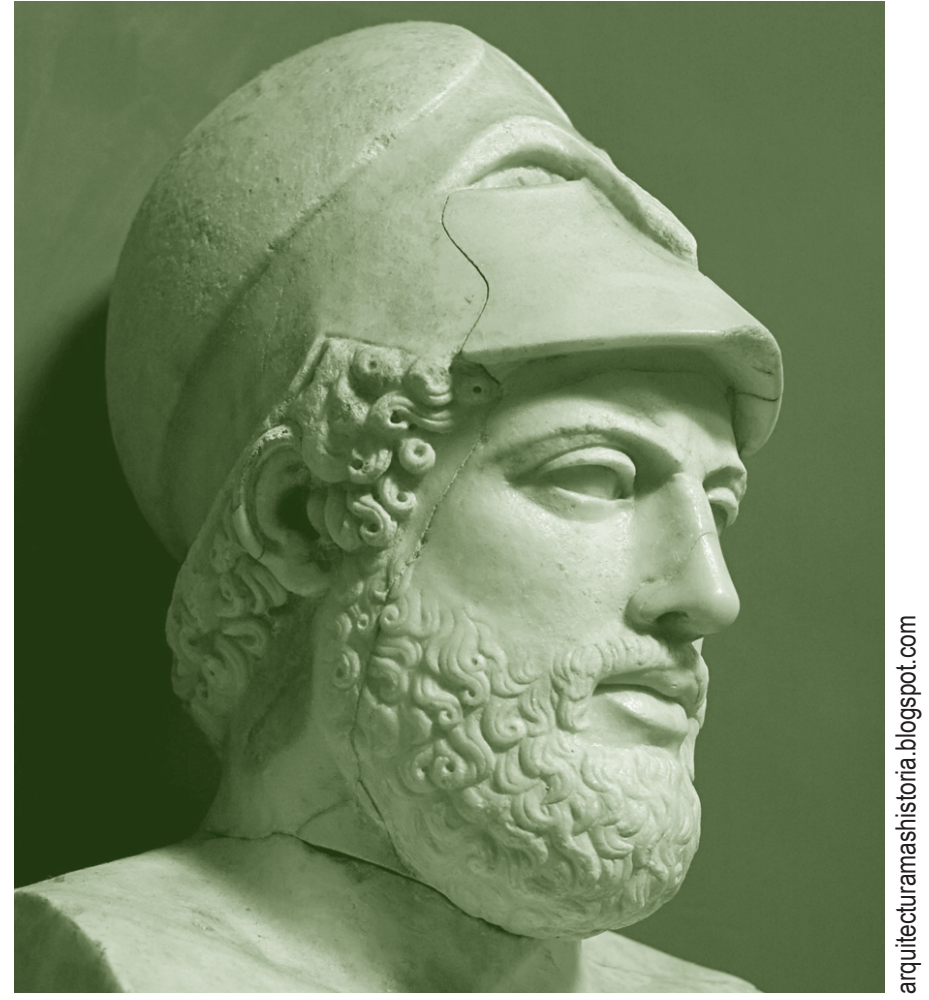

de los historiadores en la Antigua Grecia nos da la idea de que la Historia aparece en esos tiempos con los componentes de una ciencia pero también con los de un género de la escritura. La Historia a partir de Heródoto será en delante historia escrita.

La polis como ámbito de la política hizo posible la aparición de la Historia en el siglo V.a.C.

De igual modo se afirma que los primeros historiadores escriben sus historias para resistir el tiempo, para que no se desvanezca la memoria de los hechos.

3 Heródoto. Los nueve libros de la Historia.www.eBooks.org

4 Tucídides. Historia de la guerra del Peloponeso. Editorial Orbis .S.A. Barcelona .1986

5 Jenofonte. Anábasis.www.TodoEbook.net. 